\title{
POLÍTICAS DE FORMAÇÃO DE PROFESSORES E REGULAÇÃO DE CURSOS EM PORTUGAL E NO BRASIL
}

\author{
(D) SUZANA DOS SANTOS GOMES' \\ (D) DOMINGOS FERNANDES" \\ (D) SANDRA ZÁKIA SOUSA III
}

\footnotetext{
Universidade Federal de Minas Gerais (UFMG), Belo Horizonte-MG, Brasil; suzanasgomes@fae.ufmg.br

"Instituto Universitário de Lisboa (ISCTE), Lisboa, Portugal; domingos.fernandes@iscte-iul.pt

III Universidade de São Paulo (USP), São Paulo-SP, Brasil; sanzakia@usp.br
}

\section{RESUMO}

Esta pesquisa investigou as políticas de formação inicial de professores articuladas às políticas de avaliação de curso implementadas em Portugal e no Brasil nas últimas décadas. Trata-se de uma pesquisa descritivo-analítica de abordagem qualitativa cuja fonte de dados envolveu revisão de literatura, pesquisa documental e entrevistas com professores pesquisadores da área. Os resultados revelaram que a formação inicial de professores tem se configurado de modo complexo nos dois países, em virtude das políticas educacionais efetivadas. Desse modo, a formação docente também foi considerada política essencial para o desenvolvimento da qualidade nos sistemas educacionais.

PALAVRAS-CHAVE POLÍTICAS EDUCACIONAIS • FORMAÇÃO INICIAL DE PROFESSORES • AVALIAÇÃO DA EDUCAÇÃO • PORTUGAL. 


\section{POLÍTICAS DE FORMACIÓN DOCENTE Y REGULACIÓN DE CURSOS EN PORTUGAL Y BRASIL}

\section{RESUMEN}

Esta investigación estudió las políticas de formación inicial de docentes articuladas a las políticas de evaluación de curso implementadas en Portugal y Brasil en las últimas décadas. Se trata de una investigación descriptivo-analítica de abordaje cualitativo, cuya fuente de datos involucró revisión de literatura, investigación documental y entrevistas con profesores investigadores del área. Los resultados revelaron que la formación inicial docente se ha configurado de manera compleja en los dos países, en virtud de las políticas educacionales que se implantaron. De este modo la formación docente también ha sido considerada como una política esencial para el desarrollo de la calidad en los sistemas educacionales.

PALABRAS CLAVE POLÍTICAS DE EDUCACIÓN • FORMACIÓN INICIAL DE DOCENTES • EVALUACIÓN EDUCACIONAL・PORTUGAL.

\section{POLICIES FOR TEACHER TRAINING AND COURSE REGULATION IN PORTUGAL AND BRAZIL}

\section{ABSTRACT}

This study investigated the policies for initial teacher training, articulated in the course evaluation policies implemented in Portugal and in Brazil in recent decades. It is a descriptive-analytical study, using a qualitative approach, whose data source involved literature review, documentary research and interviews with teacher-researchers from the field. The results revealed that the initial training of teachers has been configured in a complex way, in both countries, due to the educational policies implemented. Thus, teacher training was also considered an essential policy for the development of quality in those educational systems.

KEYWORDS EDUCACIONAL POLICIES • INITIAL TEACHER EDUCATION • EDUCATIONAL EVALUATION • PORTUGAL. 


\section{INTRODUÇÃO}

As políticas de formação de professores estão presentes na agenda nacional e internacional da educação e, nas últimas décadas, foram centrais em Portugal e no Brasil. Tal fato confere importância à compreensão de marcos teóricos e conceituais, de normatizações sobre formação inicial de professores, como também de procedimentos de regulação de cursos, reconhecendo a relevância desse conhecimento para professores, gestores e profissionais da educação, visando à melhoria nos processos de ensino e de avaliação.

Nesse sentido, esta pesquisa focalizou o seguinte problema: Que políticas de formação inicial de professores e de avaliação de curso estão sendo implementadas em Portugal e no Brasil? Do ponto de vista metodológico, trata-se de uma pesquisa descritivo-analítica de cunho qualitativo, tendo como fontes de informação: a legislação sobre formação de professores e avaliação de curso, pesquisa documental e entrevista semiestruturada com professores pesquisadores. No trato analítico dos dados, adotou-se o método comparativo e a análise de conteúdo.

No campo da formação e da avaliação educacional, os estudos tendem a enfatizar demandas pela avaliação contínua dos cursos de formação e articulação de diferentes dimensões da profissão docente, que envolve, entre outros, aspectos políticos, sociais, pedagógicos, éticos e culturais (GATTI; BARRETO; ANDRÉ, 2011; MASSON, 2011; SOUSA, 2013, 2014; LOPO, 2016; FERNANDES, 2016).

Pode-se afirmar que o debate sobre a formação de professores é teórico-prático, no sentido de definir referenciais da formação e atuação desses profissionais que constituem elementos de sua identidade profissional, contudo, também é essencialmente político, uma vez que envolve opções de sujeitos e grupos que se defrontam, com base em interesses, por meio de relações de poder e embates, que não expressam uma perspectiva única, mas convivem numa relação dialética.

Este artigo está organizado em quatro seções: a primeira problematiza e justifica o tema, assim como as questões estruturantes da pesquisa. A segunda se refere ao percurso metodológico e contempla as etapas do estudo. Na terceira seção apresenta-se uma breve revisão da normatização e da regulação de cursos de formação inicial de professores em Portugal e no Brasil. Na quarta, são apresentados e analisados os depoimentos dos participantes da pesquisa. Por fim, a quinta seção destina-se a apresentar, por meio da análise comparativa, discussões sobre políticas de formação inicial de professores e avaliação de cursos. Nessa seção, por meio do cruzamento de dados, são apresentadas categorias que evidenciam pontos comuns e especificidades das políticas de formação em Portugal e no Brasil. 


\section{METODOLOGIA DA PESQUISA}

Pretendeu-se com esta pesquisa investigar as políticas de formação inicial de professores articuladas às políticas de avaliação de curso implementadas em Portugal e no Brasil nas últimas décadas por meio de estudo comparado, identificando características, especificidades e contrastes presentes nos dois contextos.

A metodologia de pesquisa envolveu duas etapas: uma teórica e outra empírica. Na primeira, realizou-se levantamento bibliográfico e documental sobre a formação inicial de professores e a avaliação de cursos por meio de livros, artigos de periódicos e publicações especializadas da área e levantamento da legislação pertinente, nos dois países, com o objetivo de obter um referencial teórico estruturado e fundamentado.

Na segunda etapa, recorreu-se ao recurso da entrevista semiestruturada. A escolha dos entrevistados se deu por meio da indicação de professores pesquisadores. Dentre os critérios utilizados, destaca-se a experiência no campo da formação docente e/ou no campo das políticas educacionais. Em Portugal foram selecionados seis pesquisadores, sendo quatro do sexo feminino e dois do sexo masculino. Quanto à titulação, todos são doutores, sendo três em Ciências da Educação, um em História, uma em Sociologia e outra em Metodologia do Ensino de Línguas. Também no Brasil, seis pesquisadores colaboraram com o estudo, sendo quatro do sexo feminino e dois do sexo masculino. Quanto à titulação, três são doutores e os demais informaram ter pós-doutorado, sendo dois em Educação e um em Sociologia. O Quadro 1 apresenta uma síntese do roteiro da entrevista, composto por dois eixos: políticas de formação e políticas de avaliação dos cursos.

\section{QUADRO 1 - Roteiro de entrevista}

\begin{tabular}{|c|c|c|c|c|}
\hline EIXOS & \multicolumn{3}{|c|}{ SUBEIXOS } \\
\hline $\begin{array}{c}\text { Políticas de formação } \\
\text { inicial de professores } \\
\text { de } \mathbf{1}^{\circ} \text { e } \mathbf{2}^{\circ} \text { ciclos da } \\
\text { educação básica }\end{array}$ & $\begin{array}{c}\text { Normatizações } \\
\text { antes das diretrizes: } \\
\text { características, limites } \\
\text { e aspectos positivos }\end{array}$ & $\begin{array}{c}\text { Normatizações pós-diretrizes: características, } \\
\text { aspectos positivos e desafios }\end{array}$ & $\begin{array}{c}\text { Principais } \\
\text { características e } \\
\text { normatizações atuais }\end{array}$ \\
\hline $\begin{array}{c}\text { Políticas de avaliação } \\
\text { de cursos }\end{array}$ & $\begin{array}{c}\text { Características das } \\
\text { políticas de avaliação } \\
\text { de cursos }\end{array}$ & $\begin{array}{c}\text { Principais objetos de } \\
\text { avaliação de cursos de } \\
\text { licenciatura }\end{array}$ & $\begin{array}{c}\text { Qualidade da } \\
\text { formação: como se } \\
\text { verifica? }\end{array}$ & $\begin{array}{c}\text { Resultados das } \\
\text { avaliações }\end{array}$ \\
\hline
\end{tabular}

Fonte: Elaboração dos autores.

No que diz respeito aos procedimentos adotados para o tratamento dos dados, as entrevistas foram transcritas e tabuladas, buscando compreender, validar e responder ao problema proposto neste estudo. A análise foi, portanto, sistemática e analógica, reinterpretando as categorias selecionadas com base nas contribuições de Bardin (2009). Nesse sentido, procurou-se realizar o estudo comparado de modo reflexivo, interpretativo e dinâmico, estabelecendo relações entre o estudo empírico e 
a fundamentação teórica (WELLER, 2017; MASSON, 2011; NÓVOA, 2009b). A triangulação dos dados foi um procedimento adotado para garantir consistência e precisão sobre o problema investigado.

Sobre a perspectiva comparada, pode-se afirmar que a comparação é um instrumento fundamental de análise, uma vez que aguça a capacidade de descrição, desempenhando papel central na formação de conceitos ao permitir a identificação de semelhanças e especificidades, contribuindo para a descoberta indutiva e para a construção teórica. Assim, pode-se afirmar que a finalidade dos estudos comparados é estabelecer uma relação dialógica entre pesquisas, incentivando a formação de redes de pesquisadores, no sentido de fortalecer as bases de dados e os instrumentos de análise (WELLER, 2017; PHILLIPS; SCHWEISFURTH, 2014; NAKAMURA, 2013).

\section{POLÍTICAS DE FORMAÇÃO INICIAL DE PROFESSORES}

Vários países vêm desenvolvendo políticas e ações na área educacional, cuidando, sobretudo, dos professores, que são os sujeitos referência na promoção do processo ensino-aprendizagem e da cultura. Nas últimas décadas, países da América Latina - entre eles, Brasil, Chile, Argentina e Colômbia - e da Europa - como França, Itália e Portugal - tomaram medidas efetivas na formação de professores, propiciando carreiras mais atrativas.

A formação inicial de professores passou por reformulações traduzidas em mudanças no processo formativo, na estrutura curricular e nos planos de estudo, regulados pelo sistema que tem subjacente determinado modelo de formação. A seguir, serão apresentadas as diretrizes para a formação de professores em Portugal e no Brasil.

\section{A formação inicial de professores de $1^{\circ}$ e $2^{\circ}$ ciclos em Portugal}

As mudanças políticas introduzidas em Portugal pelo Processo de Bolonha acentuaram a complexidade dos desafios na educação superior, bem como na formação de professores. Pode-se afirmar que a Declaração de Bolonha (1999) e os compromissos decorrentes da criação do Espaço Europeu do Ensino Superior (EEES) promoveram mudanças na estrutura dos cursos e no funcionamento das instituições. Dentre essas mudanças, destacam-se demandas por avaliação de cursos e a ênfase na qualidade.

No que diz respeito à formação inicial de professores, foram implantadas transformações na estrutura dos ciclos de estudo, que passaram a ter regulamentação própria e institucionalização de uma cultura de avaliação.

Em 2007 foi regulamentado o Decreto-lei n. 43 (PORTUGAL, 2007a), que promovia alterações na estrutura, na organização e na operacionalização dos cursos de formação. As mudanças na formação foram justificadas pelas demandas voltadas 
para a garantia de maior qualidade no ensino e, consequentemente, pela promoção de melhorias nos resultados de aprendizagem em todos os níveis de ensino. Essa legislação atribuiu relevância à avaliação dos cursos, como procedimento para garantir a qualidade, prevendo-se diferentes ações formativas, de melhoria dos processos, pautadas no controle e na regulação, articulando-se processos de avaliação externa com processos de avaliação interna.

A tarefa de avaliação externa foi atribuída à Agência de Avaliação e Acreditação do Ensino Superior (A3ES), com o objetivo de garantir o acompanhamento dos processos internos de autoavaliação das instituições. Essa agência, criada pelo Decreto-lei n. 369/2007 (PORTUGAL, 2007b), é responsável pela avaliação dos cursos, da qual podem resultar: uma acreditação por seis anos; uma acreditação condicional (exigindo o cumprimento de condições); ou uma não acreditação do curso.

Constata-se a relevância atribuída à avaliação dos cursos, presente nas políticas para o ensino superior como procedimento adotado, a fim de garantir a qualidade, sendo possível identificar, nos documentos legais que estruturam essas políticas, diferentes ações formativas, de melhoria dos processos, pautados, também, no controle e na regulação que articulam processos de avaliação externa com processos de avaliação interna.

Coerente com essa perspectiva, os Decretos-lei n. 74/2006 (PORTUGAL, 2006), n. 369/2007 (PORTUGAL, 2007b) e n. 107/2008 (PORTUGAL, 2008) e a Lei n. 38/2007 (PORTUGAL, 2007c) são documentos que explicitam as políticas em Portugal implementadas pelo Processo de Bolonha. A avaliação e a acreditação dos ciclos de estudos são apresentadas nos documentos como procedimentos fundamentais para o funcionamento e o financiamento dos cursos e das instituições.

De acordo com a legislação vigente, para os estudantes adquirirem habilitação profissional para a docência ${ }^{1}$ é necessário concluir um curso de licenciatura em educação básica e cursar um dos três mestrados de habilitação para a docência: Mestrado em Educação Pré-escolar; Mestrado em Educação Pré-escolar e em Ensino do $1^{\circ}$ Ciclo do Ensino Básico (CEB); e Mestrado em Ensino do $1^{\circ}$ e $2^{\circ}$ CEB.

Em 2014 foi aprovado, pelo Decreto-lei n. 79 (PORTUGAL, 2014, p. 2819), um novo regime jurídico de habilitação profissional para a Docência na Educação Pré-Escolar e nos ensinos básico e secundário, implantando novas alterações na

1 A habilitação profissional para a docência é, atualmente, conferida por meio de uma licenciatura em Educação Básica, comum a quatro domínios possíveis (Educador de Infância, Professor do Ensino Básico: $1^{\circ} \mathrm{Ciclo}$, Educador de Infância e Professor do Ensino Básico: $1^{\circ} \mathrm{Ciclo} \mathrm{e} \mathrm{Professor} \mathrm{do} 1^{\circ}$ e do $2^{\circ}$ Ciclos do Ensino Básico), e de um mestrado em Ensino, no âmbito desses mesmos domínios. Os atuais processos formativos centram-se nos componentes de Formação Educacional Geral, Didáticas Específicas, Iniciação à Prática Profissional, Formação Cultural, Social e Ética, Formação em Metodologias de Investigação Educacional e Formação na Área da Docência (Decreto-lei n. 43/2007, de 22 de fevereiro). 
operacionalização dos currículos de formação inicial de professores. Assim, o referido diploma mantém o modelo bietápico ou sequencial que organiza a formação em dois ciclos de estudos - licenciatura e mestrado -, sendo a licenciatura em Educação Básica condição de ingresso nos mestrados.

\section{A formação inicial de professores no curso de Pedagogia no Brasil}

Inserida em um contexto nacional de mudanças políticas, transformações na sociedade e consequentemente exigências educativas, a década de 1980 exigia um profundo debate sobre o sentido dos cursos de Pedagogia, principalmente pela indefinição do caminho formativo que seria adotado, ainda marcado por inúmeros dilemas decorrentes da condição de conflito e ambiguidade de concepções, que até então marcava o curso.

No final dessa década, mais especificamente em 1988, a Constituição Federal demarca atribuições e responsabilidades relacionadas aos sistemas educacionais, incidindo, portanto, naqueles responsáveis por sua organização e funcionamento cotidiano, sobretudo nos princípios de acesso, permanência e qualidade, sob a premissa da colaboratividade dos entes federados. Torna-se relevante destacar que $o$ movimento de discussão e de elaboração das diretrizes do curso de Pedagogia tem um marco importante em 1998, quanto à Comissão de Especialistas de Pedagogia, instituída para elaborar as diretrizes do curso, e que desencadeou amplo processo de discussão, em âmbito nacional (AGUIAR et al., 2006).

No entanto, apenas em 1996, com a edição da Lei de Diretrizes e Bases da Educação Nacional (LDBEN n. 9.394) (BRASIL, 1996), o tratamento para a formação dos profissionais da educação passou a ser indicado, especificamente no capítulo VI da LDB. Assim, denunciava-se a emergência de uma definição mais precisa para a formação daqueles que passariam a ser chamados de profissionais responsáveis pelos processos de gestão educacional, em vez de especialista em educação.

Nesse sentido, após longos debates entre representantes dos órgãos oficiais, de associações e representantes dos professores, sem consenso, ocorridos nas décadas de 1980 e 1990, foram aprovadas as Diretrizes Curriculares Nacionais (DCN) para o curso de Pedagogia, por meio dos Pareceres do Conselho Nacional de Educação/ Conselho Pleno (CNE/CP) n. 5/2005 (BRASIL, 2005), CNE/CP n. 3/2006 (BRASIL, 2006a) e da Resolução CNE/CP n. 1/2006 (BRASIL, 2006b), os quais marcam o final de uma importante etapa no processo de discussão da formação dos professores. $\mathrm{O}$ vigoroso embate suscitado certamente proporcionou avanços e esclarecimentos para a área e, inevitavelmente, questionamentos (GATTI, 2010; BRZEZINSKI, 2007, 2009; SHEIBE, 2007; PIMENTA, 2006; LIBÂNEO, 2006; AGUIAR et al., 2006).

A promulgação das diretrizes para o curso de Pedagogia, em 2006, não conseguiu contemplar as posições antagônicas desses desacordos e efetivou finalmente 
sua centralidade na formação de professores para a educação infantil e anos iniciais do ensino fundamental. Compete, ainda, ao curso, o desenvolvimento de competências para o ensino nos cursos de nível médio, na modalidade normal; o ensino na educação profissional na área de serviços e apoio escolar; as atividades de organização e gestão educacionais; e as atividades de produção e difusão do conhecimento científico-tecnológico do campo educacional.

As mudanças curriculares no curso de Pedagogia fazem parte de uma ampla, longa e discutida reforma na organização dos cursos de graduação e na formação dos profissionais da educação no Brasil. Das orientações gerais contidas no documento, é possível depreender os princípios orientadores adotados na reestruturação curricular proposta: flexibilidade curricular; dinamicidade do currículo; adaptação às demandas do mercado de trabalho; integração entre graduação e pós-graduação; ênfase na formação geral; definição e desenvolvimento de competências e habilidades gerais.

Novos desafios para a formação de professores foram colocados com a aprovação das DCN para a formação inicial e continuada dos profissionais do magistério da educação básica, estabelecidas pelo Parecer CNE/CP n. 2/2015 (BRASIL, 2015a), e pela Resolução CNE/CP n. 2/2015 (BRASIL, 2015b), que definem cursos de licenciatura, cursos de formação pedagógica para graduados e cursos de segunda licenciatura e para a formação continuada de professores.

Pode-se afirmar que essas diretrizes apresentam um elemento diferenciado em relação à anterior, pois procura-se enfatizar também a formação inicial e continuada dos professores, considerada elemento fundamental para o bom exercício profissional (MANDARINO; BELTRÃO, 2018; HONÓRIO et al., 2017; AGUIAR, 2017; DOURADO, 2015).

Assim, a Resolução n. 2/2015 (BRASIL, 2015b) ampliou a carga horária mínima de todos os cursos de licenciatura, que passaram de 2.800 para 3.200 horas, estabeleceu uma proporção maior de conteúdos pedagógicos e práticos durante a formação, o que, em tese, procura corrigir uma lacuna histórica nos cursos de licenciatura que em sua maioria caracterizam-se pela ausência de uma formação voltada para a docência.

De acordo com Dourado (2015), as DCN recomendam projetos próprios de formação com ênfase na articulação entre educação básica e superior, e ainda sugerem a institucionalização da formação de profissionais do magistério no Plano de Desenvolvimento Institucional (PDI), no Projeto Pedagógico Institucional (PPI) e nos Projetos Pedagógicos de Curso (PPC).

Torna-se relevante acrescentar que foi editada a Resolução CNE/CP n. 2, de 20 de dezembro de 2019 (BRASIL, 2019b), que revoga a Resolução CNE/CP n. 2/2015 (BRASIL, 2015b) e aprova novas DCN para a formação inicial de professores para a 
educação básica e institui a Base Nacional Comum para a formação inicial de professores da educação básica (BNC-Formação), com fundamento no Parecer CNE/CP n. 22/2019 (BRASIL, 2019a). As DCN das licenciaturas fazem referência à Base Nacional Comum Curricular (BNCC) da Educação Básica, em cumprimento ao art. 11 da Lei n. 13.415, de 16 de fevereiro de 2017 (BRASIL, 2017), que deu nova redação ao art. 62, § $8^{\circ}$, da LDB n. 9.394, de 20 de dezembro de 1996, ao estabelecer o prazo de dois anos para que os currículos dos cursos de formação tenham por referência a BNCC.

Para muitas associações e instituições formadoras, a Resolução CNE/CP n. 2, de 20 de dezembro de 2019 (BRASIL, 2019b), descaracteriza a formação de professores prevista na Resolução CNE/CP n. 2/2015 (BRASIL, 2015b) e não contempla princípios fundamentais, entre eles: sólida formação teórica e interdisciplinar; unidade teoria-prática; gestão democrática; formação inicial e continuada articulada ao compromisso social da universidade com base no tripé indissociável ensino-pesquisa-extensão; e a construção de um projeto institucional de formação (BAZZO; SCHEIBE, 2019).

\section{ANÁLISE COMPARADA DA FORMAÇÃO INICIAL DE PROFESSORES EM PORTUGAL E NO BRASIL}

Nesta seção serão apresentados alguns aspectos da análise comparada realizada sobre as políticas de formação inicial de professores em Portugal e no Brasil. Os resultados têm como referência a revisão de literatura, a legislação e as entrevistas. Considerando os limites deste artigo, foram selecionados alguns depoimentos para serem apresentados. Por meio da triangulação dos dados foi possível chegar à delimitação de categorias de análises comuns e específicas, identificadas no estudo.

Investigar políticas educacionais sob a perspectiva comparada demanda revalorizar o conceito de espaço-tempo de modo a compreender melhor a historicidade dos fenômenos educacionais, que não são realidades naturais, mas construções sociais impregnadas de valores que disputam a representação da política no âmbito local e global. Assim, a comparação de políticas públicas de educação é uma história de sentidos e não a busca de regularidades entre as sociedades. Portanto, os estudos comparados passam a expressar os sentidos que os diferentes contextos dão às suas ações (GIRAUD, 2009).

\section{Formação inicial de professores: categorias comuns entre Portugal e Brasil}

A primeira categoria comum entre Portugal e Brasil é "Garantia da qualidade da formação inicial de professores". Pode-se afirmar que a formação inicial de professores tanto em Portugal quanto no Brasil vem se ajustando ao discurso de qualidade que tem se constituído em uma das principais marcas dos discursos políticos nas últimas décadas. 
Na legislação portuguesa, as mudanças na formação inicial de professores são justificadas pela necessidade de garantir um corpo docente qualificado (DL n. 43/2007 e n. 79/2014), buscando assegurar qualidade e melhores resultados de aprendizagem nos diferentes níveis de ensino.

Estão previstos mecanismos de garantia da qualidade da formação que envolvam o monitoramento das mudanças realizadas por meio tanto da autoavaliação institucional quanto da avaliação externa realizada pela A3ES (FERNANDES, 2015, 2016).

Os trechos extraídos de depoimentos de participantes, ${ }^{2}$ em Portugal e no Brasil, destacam a questão da qualidade da formação inicial, conforme se apresenta a seguir:

A qualidade dos cursos é no fundo verificada com base, sobretudo, nessa avaliação externa e nos sistemas internos de garantia de qualidade. Eu penso que os processos de avaliação estão interferindo positivamente na formação inicial de professores. Com todas as críticas que nós possamos fazer aos sistemas de avaliação externos e internos, eles existem. Essas avaliações funcionam ou podem funcionar como formas de regulação e monitoramento da qualidade e oportunidades da melhoria dos cursos.

[...] Eu diria, pela minha experiência, [...] que essas avaliações podem ser para quem está sendo avaliado momentos importantes de reflexão sobre a qualidade da formação. (Profa. lara, Instituição 5, Portugal)

Inicialmente, eu gostaria de destacar que qualidade é um conceito polissêmico, ou seja, a qualidade pode ser compreendida por diferentes facetas. Nesse sentido, existem diferentes vertentes para entender a qualidade que vão se diferenciar pela concepção de mundo, de homem e de sociedade presente em determinado projeto. Quando penso sobre a formação, sobre a qualidade da formação, eu tenho que perguntar: Que projeto pedagógico orienta essa formação? Que concepção de docência fundamenta esse projeto pedagógico? Que perfil de egresso está preconizado no curso? Quais são as condições objetivas presentes nessa formação. E, além disso, é preciso identificar como esse curso de formação se articula ou não com as instituições de educação básica. Que horizonte formativo foi pensado para o curso de Pedagogia? (Prof. Davi, Instituição 1, Brasil)

Coerente com essa perspectiva, no Brasil, o sistema de controle e de melhoria da qualidade foram sendo implementados nos diversos serviços públicos juntamente com a implantação do sistema de avaliação que mede a qualidade. Nesse sentido, também se constatam diferentes significados de qualidade. E, para o Sistema Nacional de Avaliação da Educação Superior (Sinaes), tal qualidade remete à busca pela eficácia e efetividade que se alcança por meio de critérios definidos pelos

2 Adoção de nomes fictícios para preservar a identidade dos professores pesquisadores. 
instrumentos de avaliação. Além disso, o sistema propõe, como princípio: a autoavaliação, o respeito à autonomia e a missão institucional.

Para os docentes, a qualidade se traduz em uma gama de sentidos: corpo docente preparado, infraestrutura adequada, atendimento à realidade dos ingressantes, formação com vistas à preparação do egresso para atuar na realidade diversificada das escolas, entre outros (SOUSA, 2014; BARRETO, 2015).

Assim, a promoção da qualidade dos cursos de formação inicial de professores compete às instituições, sobretudo por meio de seus órgãos de direção e coordenação pedagógica e científica, recorrendo aos meios e incentivos financeiros disponibilizados e agindo no âmbito do quadro legal definido. Um dos instrumentos de promoção da qualidade utilizado para o efeito é a avaliação institucional e de cursos. Essa avaliação é assegurada por associações das instituições de cada setor, sob a coordenação global da A3ES em Portugal e do Ministério da Educação/Instituto Nacional de Estudos e Pesquisas Educacionais Anísio Teixeira (MEC/Inep) no Brasil. Trata-se de uma autoavaliação realizada inicialmente por uma comissão designada pela instituição, que, posteriormente, é utilizada como importante ponto de partida por uma comissão de avaliação externa.

Nos dois países, a garantia de um padrão de qualidade na formação de professores é um alvo a ser alcançado e envolve interlocução entre as instâncias formadoras, visando a desenvolver ações articuladas em defesa da qualidade na formação. A definição de políticas voltadas para a formação dos profissionais passa pela garantia da qualidade, devendo ser assumida em regime de colaboração pelos entes federados nos respectivos sistemas de ensino.

A segunda categoria comum entre os dois países é "Avaliação e regulação dos cursos de formação inicial de professores”. Em Portugal, é possível situar a importância conferida à avaliação e seu papel de destaque nas políticas educativas. A visão reformadora presente no ensino superior em geral, e na formação inicial de professores em particular, aprova um papel de primeira ordem aos mecanismos de regulação interna da qualidade, assim como controle externo dos processos de mudança. Essa tarefa de avaliação externa foi atribuída à A3ES, esperando-se que essa agência dinamizasse os processos internos de autoavaliação das instituições e dos cursos ofertados (AFONSO, 2010; FERNANDES, 2015, 2016; GOMES, 2005).

Para Esteves (2015), a criação do sistema de acreditação da formação inicial de professores exigia que as instituições submetessem seus programas a um processo de apreciação externa de sua capacidade de cumprir com os requisitos de qualidade associados ao desempenho da atividade docente. Pretendia-se igualmente que a avaliação dos programas não se limitasse a uma verificação do cumprimento de normas legais, mas que produzisse um julgamento acerca da qualidade dos recursos, dos processos e dos resultados da formação ministrada. Desse modo, a acreditação 
não poderia ser limitada à análise do respectivo projeto educativo, mas deveria contemplar seu desenvolvimento em longo prazo.

No Brasil, a Lei n. 10.861, de 14 de abril de 2004 (BRASIL, 2004), instituiu o Sinaes, com o objetivo de melhorar a qualidade da educação superior, a orientação da expansão de sua oferta, o aumento permanente da sua eficácia institucional, efetividade acadêmica e social e, especialmente, a promoção dos compromissos e responsabilidades sociais das instituições, por meio da valorização de sua missão pública, da promoção dos valores democráticos, do respeito à diferença e à diversidade, da afirmação da autonomia e da identidade institucional.

Nesse contexto, o Inep conduz o sistema de avaliação de cursos superiores no Brasil, incluindo os cursos de formação inicial de professores, produzindo indicadores e um sistema de informações que subsidia tanto o processo de regulamentação, exercido pelo MEC, como a garantia de transparência dos dados sobre a qualidade da educação superior para toda a sociedade.

Nesse contexto, cabe reiterar, ainda, que o Exame Nacional de Desempenho dos Estudantes (Enade) foi criado pelo MEC, por meio do Sinaes, como uma forma de avaliação do corpo discente das instituições e uma forma documental de apresentar os resultados de desempenho dos alunos nos diversos cursos de graduação ministrados no Brasil. Por ter esse caráter avaliativo e comprobatório, é possível inferir que esse tipo de iniciativa pode se traduzir numa ação relevante para promover melhorias, reavaliar metodologias de ensino, readequar os conteúdos programáticos de cursos de graduação, avaliar o desempenho nas práticas de ensino e ser o fator preponderante para avaliação institucional obrigatória, que comprova a qualidade do serviço de ensino prestado junto aos órgãos responsáveis (GOMES; MELO, 2018).

São características principais do Sinaes avaliar instituições e cursos por meio de avaliações externas de comissões de pares, e internamente por uma Comissão Própria de Avaliação (CPA), que deve ser atuante em cada instituição e com representatividade dos segmentos da comunidade acadêmica: representantes dos corpos discente, docente, técnico e membros da sociedade civil.

Os depoimentos a seguir revelam aspectos do sistema de avaliação nos dois países:

Em Portugal, a avaliação dos cursos é realizada pela Agência A3ES, que faz a acreditação dos cursos. Esse instituto público avalia os cursos e certifica se eles cumpriram os requisitos, se positivo, são certificados para funcionar por seis anos, se não cumpriram, podem ser extintos ou é dado um prazo para que introduzam as alterações indicadas. Inicialmente temos uma autoavaliação, depois é feita uma avaliação externa por essa agência e dependendo do juízo avaliativo os cursos podem ser acreditados. Portanto, todos esses cursos são avaliados, entre eles, os que 
formam professores. Sobre a autoavaliação, a comissão do curso preenche um relatório que é enviado para a agência, alguns componentes são institucionais, preenchidos pela reitoria, outros componentes são das comissões de curso. Depois esses relatórios são devolvidos às instituições com pareceres. Se houver discordâncias ou incoerências, esse parecer pode ser contestado. (Prof. Valter, Instituição 3, Portugal)

Temos marcos regulatórios nas políticas educacionais e gestão da Educação Superior no Brasil e as diretrizes do curso de Pedagogia, por exemplo, se colocam nesses marcos. É esperado que todo o processo de autorização e de reconhecimento de cursos considere as diretrizes como elemento crucial nesse processo. Para os processos de avaliação, você tem uma série de medidas que estão articuladas ao Sinaes e, especificamente, você tem instrumentos de avaliação do conjunto dos cursos. Um dos elementos do Sinaes é o Enade, a avaliação dos estudantes dos diferentes cursos. Mas o sistema nacional é muito mais amplo, ele deve avaliar as condições institucionais e até os impactos políticos pedagógicos. (Prof. Davi, Instituição 1, Brasil)

Como se vê, a avaliação proposta pelo Sinaes e pela A3ES, em seus aspectos globais, pretende qualificar cursos e programas, além de regular e aferir desempenho. Também envolve avaliações internas e externas e apresenta resultados mensuráveis. Esses resultados buscam demonstrar quantitativamente o desempenho da instituição, tanto para cada curso individualmente quanto para a instituição como um todo.

Em se tratando de avaliação, é imprescindível reconhecer que nenhum processo avaliativo é capaz de cobrir todas as dimensões que compõem o conceito de qualidade da educação superior. Acrescenta-se a esse reconhecimento o fato de que uma avaliação integra um ciclo de gestão que se completa com as etapas de planejamento e implementação. Por esse motivo, qualquer sistema avaliativo precisará ser constantemente avaliado, para que continue a ser útil àqueles que dependem de suas informações, de caráter diagnóstico ou não. Todo trabalho oriundo da avaliação interna e externa só se justifica se os resultados forem efetivamente utilizados nos diversos níveis de tomada de decisão: alunos, curso, instituição, governo e sociedade (AFONSO, 2010; BONAMINO; SOUSA, 2012; SOUSA, 2013; FERNANDES, 2016).

Nesse sentido, informações coletadas por meio de processos de avaliação, tanto em Portugal quanto no Brasil, devem ser utilizadas para orientação institucional, assim como para sustentar políticas públicas relativas à educação superior. Além disso, dados obtidos também devem ser úteis à sociedade, sobretudo para estudantes que os tomam como referência quanto às condições de cursos e de instituições.

A terceira categoria identificada no estudo foi "Desafio da articulação entre teoria e prática”. Verificou-se que, nos modelos curriculares de grande predominância 
em Portugal e nos países europeus, no período da universitarização, a formação teórica tem expressiva relevância, mas era trabalhada, afastada de preocupações práticas que os professores enfrentavam em sua atividade laboral (FORMOSINHO, 2009; ROLDÃO, 2009; NÓVOA, 2009a).

Nesse sentido, constatou-se uma tensão entre as dimensões prática e teórica nos processos formativos de professores. Pode-se afirmar que a dicotomia teoria e prática representa um desafio crucial da formação de professores, porque em torno dela são organizados inúmeros desafios da formação a serem enfrentados pelas instituições formadoras na implementação do seu projeto de curso (ESTEVES, 2015; FLORES, 2015; ROLDÃO, 2009).

Da mesma maneira, no Brasil, alguns documentos enfatizam ser necessário superar a histórica dicotomia entre teoria e prática na formação inicial de professores e o divórcio entre a formação pedagógica e a formação no campo dos conhecimentos específicos (BRASIL, 2006b, 2015b). Entretanto, apesar de as recomendações de pesquisadores do campo da formação de professores enfatizarem demandas pela superação dessa dicotomia, permanece como desafio romper/minimizar o distanciamento entre a universidade e a escola (PIMENTA et al., 2017; LIBÂNEO, 2017; GATTI et al., 2010; ANDRÉ, 2010).

Depoimentos de professores pesquisadores também abordaram o dilema da articulação entre teoria e prática.

[...] Um grande desafio que eu creio que temos é o de articular melhor os diversos componentes que constituem os mestrados de ensino e relacioná-los com a prática profissional. Há pessoas que estão, por exemplo, a dar uma disciplina de História da Educação, mas não levam em conta que deveriam orientar essa disciplina para a formação de um professor e não para a formação de um historiador. Para que isso ocorra seria importante pensar: Que sentido tem uma disciplina de História da Educação no curso de formação de professores? O que é relevante para o exercício da docência? Portanto, deverá fazer algumas escolhas. Esse exemplo ilustra o que eu entendo por articulação dos vários componentes a serviço da prática profissional. (Profa. Marta, Instituição 1, Portugal)

Então, eu penso que a resolução é contemporânea às discussões do campo, aos movimentos de reformulação e traz um princípio fundante para formação que é a busca da organicidade. E, a partir daí, deve-se enfatizar a relação teoria e prática e processos mais orgânicos, de modo que não haja uma segmentação entre a didática e a prática de ensino, os conteúdos e as metodologias. (Profa. Gabriela, Instituição 6, Brasil)

Em consonância com esses excertos, constata-se que não é suficiente garantir a ampliação da carga horária, mas, sobretudo, garantir relações dialógicas entre 
teoria e prática. Outro aspecto estreitamente relacionado com relação entre teoria e prática é a aprendizagem de procedimentos investigativos e de problematização da realidade. Coerente com essa perspectiva, a interdisciplinaridade e a transversalidade são fundamentais para a busca de maior articulação teórica e prática. Além disso, outra proposta importante seria uma atuação coletiva dos futuros professores no espaço escolar, favorecendo trocas reflexivas sobre suas práticas, qualificando sua atuação e proporcionando um processo contínuo de formação. Para tanto, o eixo da organização curricular da formação de professores deveria ser dado pela escola, tomando a própria prática educativa como ponto de partida e de chegada.

Formação inicial de professores: categorias contrastantes entre os dois países

A metodologia comparada, centrada nos aspectos contrastantes, tem revelado sua utilidade crescente no campo da educação e em áreas afins. Segundo Geertz (2000), a análise do contraste permite abarcar a diversidade e as especificidades das instituições sociais. Nessa perspectiva, nos limites deste artigo, apresentam-se algumas categorias contrastantes identificadas entre os dois países.

A categoria "Habilitação para a docência via mestrado profissional" foi considerada específica de Portugal. Como país membro da União Europeia, Portugal acatou a recomendação, no contexto do Processo de Bolonha em 2006, de exigir aos candidatos à entrada na profissão docente no ensino público, privado e cooperativo, o grau acadêmico de mestrado em Ensino, justificada como forma de oferecer oportunidades de prosseguimentos de estudos aos futuros professores, por meio de uma formação especializada, bem como elevar, ainda mais, o nível de certificação e de qualidade dos educadores de infância e dos professores dos ensinos básico e secundário no quadro da melhoria da qualidade do ensino e de valorização de seu estatuto profissional (FLORES, 2015).

O depoimento de uma professora pesquisadora de Portugal atesta a relevância dessa categoria:

Sobre a formação de professores pós-Bolonha, a primeira característica a
salientar é que toda a formação de educadoras de infância, professores do
$1^{\circ}, 2^{\circ}, 3^{\circ}$ ciclo, do ensino secundário, passou a ser efetivada com o mes-
trado. Ou seja, do ponto de vista acadêmico, houve uma promoção, uma
elevação do grau acadêmico. Assim, seguindo o modelo geral que o país
adotou para o ensino superior, todos os cursos de formação de professores
passaram a ter duas etapas. Uma primeira etapa, correspondente à obten-
ção do grau de licenciatura e a segunda etapa, correspondente à obtenção
do grau de mestrado. (Profa. Celia, Instituição 4 , Portugal)

Com essa medida, Portugal pretende realizar um processo de formação inicial de professores integrado e articulado com a dimensão da formação especializada 
e contínua, desenvolvida ao longo da carreira: a) licenciatura em Educação Básica ( $1^{\circ}$ ciclo, com duração de 3 anos); b) mestrado em Ensino ( $2^{\circ}$ ciclo, com duração de 2 anos); e c) um período probatório, de indução profissional (2 a 3 anos de duração). A posse desses títulos que os professores precisam comprovar é condição indispensável para exercer a docência e permitir o acesso ao exercício da atividade docente na educação básica.

Ressalta-se que, enquanto em Portugal o futuro professor tem a opção de cursar apenas Educação Pré-escolar ou Educação Pré-escolar e em Ensino do $1^{\circ}$ (CEB) ou Ensino do $1^{\circ}$ e $2^{\circ} \mathrm{CEB}$ - que corresponde aos anos iniciais do ensino fundamental -, no Brasil, a formação para a educação infantil e anos iniciais são ofertados no mesmo curso. Desse modo, verificou-se maior coerência na organização curricular do curso de formação inicial de professores em Portugal, ao passo que no Brasil ficou evidenciada uma estrutura fragmentada, superficial e generalista marcada pela indefinição do campo pedagógico, dispersão do objeto da pedagogia e da atuação profissional docente.

Nesse sentido, os resultados desta pesquisa coincidem com resultados de outros estudos que evidenciam as fragilidades curriculares presentes no curso de Pedagogia, uma vez que os conhecimentos profissionais ofertados não têm garantido as competências profissionais. Consequentemente, ao final do curso, os egressos têm vivenciado uma relação de insegurança quanto à atuação profissional (LEITE et al., 2018; GATTI; BARRETO; ANDRÉ, 2011).

Nesse contexto de estudo, a Categoria "Docência como base da formação profissional" é, pois, categoria específica da formação inicial de professores no Brasil. Diante disso, pode-se afirmar que a normatização do curso de Pedagogia prevê a formação do docente e do pedagogo (BRASIL, 2006a, 2006b). No entanto, considerando a complexidade e a amplitude envolvidas nesse projeto de formação, o que se evidencia, por meio da revisão de literatura, é que não se forma adequadamente nem o pedagogo nem o docente.

A ênfase na docência justifica-se nas referidas diretrizes, por ser considerada a base da formação do pedagogo. Essa posição está em consonância com os grupos que defenderam essa orientação legal, entre eles a Associação Nacional pela Formação dos Profissionais da Educação (Anfope) e o Fórum Nacional de Diretores das Faculdades de Educação (Forumdir), entendendo que essa ênfase supera a fragmentação observada na formação do pedagogo (AGUIAR et al., 2006; SHEIBE, 2007).

De acordo com o Parecer CNE/CP n. 5/2005, a docência compreende as atividades pedagógicas inerentes ao processo de ensino e de aprendizagens, além daquelas próprias da gestão dos processos educativos em ambientes escolares e não escolares, como também na produção e disseminação de conhecimentos da área da educação (BRASIL, 2005). 
No entanto, Pimenta (2006) e Libâneo (2006) teceram críticas ao fato de a docência configurar-se como a base da formação desse profissional, expresso no Manifesto dos Pioneiros da Educação Nova, organizado em 2006 (MANIFESTO DOS PIONEIROS, 2006). Assim, Pimenta $(2006,2017)$ e Libâneo $(2006,2017)$ se posicionaram a favor da base do curso de Pedagogia e dos profissionais da educação em torno dos conhecimentos pedagógicos, e não da docência, uma vez que esta seria uma modalidade da atividade pedagógica.

Essa questão é polêmica, e os depoimentos de professores revelam alguns embates, como:

Nos primeiros anos da década de 1980 começaram a ocorrer mudanças em alguns estados na formulação do curso de Pedagogia, nessa época começou a aparecer uma ideia que depois acabou sendo o ponto da Anfope na defesa da docência: "A formação básica de todo educador deve estar centrada na docência". [...] Em 1990 eu era membro da Anfope, mas eu discordava dessa posição. [...] Nesse congresso eu defendi três pontos distintos: a base da formação do professor é a formação pedagógica e não a formação docente, entendendo que a formação docente se subordina à formação pedagógica. Segundo ponto, eu era favorável às habilitações, porque elas caracterizavam o que eu chamava pedagogia stricto sensu. A minha tese é a seguinte: todo trabalho docente é trabalho pedagógico, mas nem todo trabalho pedagógico é trabalho docente. Em sintonia com essa perspectiva, comecei a defender dois cursos de Pedagogia: um curso de licenciatura para formar professores e outro curso, denominado bacharelado em Pedagogia. (Prof. Leonardo, Instituição 2, Brasil)

Quanto aos limites, o principal problema é a abrangência do curso, que é uma ousadia. Impossível dar conta de tantas dimensões. Penso que formar o pedagogo não corresponde ao mesmo movimento de formar o professor, ainda que a docência seja a base profissional. (Profa. Gláucia, Instituição 4, Brasil)

Acerca dessa discussão tem-se, também, o posicionamento de Libâneo (2017). O autor defende que o curso de Pedagogia deveria priorizar a produção de conhecimentos pedagógicos. Afinal, o fenômeno educativo deve ser compreendido pelos pedagogos em sua complexidade, ou seja, não de modo isolado e estático, mas como um processo articulado a vários fatores, entre eles, o aluno em seu processo de socialização e aprendizagem e os sujeitos de formação.

A docência, no marco do movimento dos educadores, foi tomada, compreendida e defendida como base da formação dos profissionais da educação, como meio de superar a fragmentação do processo formativo e a dicotomia presente em sua identidade, se especialista ou professor. Nesse sentido, as DCN do curso de Pedagogia enfatizam a docência como elemento definidor dessa identidade. 


\section{CONSIDERAÇÕES FINAIS}

Pretendeu-se neste estudo investigar as políticas de formação inicial de professores articuladas às políticas de avaliação de curso implementadas em Portugal e no Brasil nas últimas décadas. Ao concluir este artigo, considera-se relevante tecer algumas considerações obtidas.

Uma primeira consideração diz respeito à formação inicial de professores, evidenciando especificidade e fundamentos. Pode-se afirmar que a formação inicial de professores tanto em Portugal quanto no Brasil revela desafios a serem assumidos na contemporaneidade. Nas últimas décadas, Portugal passou por mudanças no modelo de formação, na organização curricular e nos modos de regulação e certificação profissional. No Brasil, as mudanças que ocorreram na formação inicial de professores trazem não apenas as características contextuais e conjunturais da época na qual se produziram, como também as exigências sociais, econômicas e políticas lançadas à educação e a seus profissionais. Ao mesmo tempo, revelam embates, anseios e expectativas dos profissionais quanto à formação docente.

A segunda consideração está relacionada ao sistema de avaliação de cursos de formação inicial de professores nas últimas décadas. Procurou-se, neste estudo, analisar a política de formação, identificando interfaces com as políticas de avaliação de curso instauradas. A opção por esse procedimento se deu em função das mudanças impulsionadas pelas reformas educacionais que vêm concedendo maior ênfase na formação, na qualidade e nos processos avaliativos dessa formação. Os professores passaram a ser vistos como sujeitos fundamentais da materialização das políticas educacionais.

Assim, verificou-se que as políticas de avaliação de curso têm de certo modo orientado o que se deve ser trabalhado na formação inicial de professores, considerada pelos gestores das políticas educacionais como a que impacta mais diretamente nos resultados educacionais. Por esse motivo, a formação inicial de professores tem atraído a atenção de pesquisadores, reconhecendo que nela reside um dos fatores decisivos para a melhoria da educação. Em outras palavras, uma formação docente de qualidade contribuirá para melhorar a qualidade do ensino e, consequentemente, a qualidade das aprendizagens e dos resultados escolares na educação básica.

Por fim, a terceira consideração diz respeito aos desafios e perspectivas que podem ser extraídos da análise comparativa entre as duas politicas de formação inicial de professores. Considera-se relevante destacar que a escolha dessa abordagem se deu pelo fato de uma das autoras ter a oportunidade de cursar o pós-doutorado em Lisboa, por meio de uma parceria firmada entre a Universidade de Lisboa e a Universidade de São Paulo. Nas últimas décadas, os estudos comparados têm ocupado um lugar de destaque nas pesquisas no campo da ciências sociais e da educação, o que enfatiza demandas sobre a comparação e seus desafios na atualidade, os motivos e o tipo de 
conhecimento produzido, as contribuições dadas para interpretação e análise da realidade e pelo fato de ser entendida como fonte de referência para desenho de políticas educacionais (WELLER, 2017; SOUZA; BATISTA, 2017; MASSON, 2011).

O levantamento teórico sobre educação comparada evidenciou a existência de limites e possibilidades. Verificou-se que seu principal objetivo não se limita a encontrar igualdades e diferenças, mas interpretar os processos educacionais, sejam eles internacionais, nacionais, regionais ou locais, a fim de descobrir novas questões e novos modos analíticos para compreensão da realidade. Entre os limites da perspectiva comparada, destaca-se a impossibilidade de transposição de experiências de um país para o outro. No arco teórico-metodológico da comparação traçado por Nóvoa (2009b), foram verificadas desde as perspectivas mais positivistas, passando por análises comparatistas mais críticas, até o oposto evidenciado nas tendências de novos elementos surgidos na contemporaneidade.

Nesse sentido, ao eleger a perspectiva comparada neste estudo, pretendeu-se compreender e analisar a complexidade das políticas de formação inicial de professores e de avaliação de curso, com a convicção de que, devido à dinâmica dos contextos, esses dados são provisórios e inconclusos obtidos no espaço-tempo dos países.

Ao abordar as políticas de formação inicial de professores e de avaliação de curso, iluminando-a com a experiência de Portugal, pretendeu-se com essas informações realizar uma análise crítica de como a realidade vem se apresentando e se modificando no Brasil, além de agregar a essa análise discussões sobre as políticas de formação e de avaliação. Espera-se que a experiência brasileira possa servir de reflexão e de análises para Portugal, considerando sua complexidade e originalidade.

Além disso, ao realizar uma comparação entre duas realidades distintas, foram criadas possibilidades de agregar pesquisadores dessas e de outras instituições interessadas nas questões da formação inicial de professores e de avaliação de curso, considerando dois países que têm afinidades históricas, culturais e educacionais, mas também diferenças. Em Portugal e no Brasil, essas questões estão constantemente em debate, sendo preocupação de pesquisadores do campo das políticas educacionais.

Assim, a formação docente nos dois países revela um campo de tensões marcado por diferentes concepções e práticas sobre formação, docência e avaliação, configurando uma trama de múltiplos fios. Essa dinâmica pode ser percebida tanto em um olhar macro como em um olhar dirigido à particularidade dos sujeitos que produzem a profissão docente nas instituições.

Verificou-se que Portugal e Brasil vêm trabalhando para promover melhorias no campo da formação inicial de professores. Trata-se de um processo em andamento, uma vez que as reformas educacionais implementadas implicam mudanças fundamentais, pois são políticas formuladas pelos governos com repercussões 
no conjunto do sistema educacional e que, portanto, demandam tempo e compromisso das instituições.

Os resultados da pesquisa revelam que a formação docente tem se configurado de modo complexo, em virtude das políticas educacionais efetivadas. Nesse sentido, permanece o desafio de que a formação inicial de professores se constitua uma etapa importante do processo de profissionalização e valorização docente.

Para concluir, a luta pela garantia da qualidade na formação de professores é compreendida como alvo a ser perseguido e demanda interlocução entre as instâncias formadoras, visando a desenvolver ações articuladas em prol da defesa da qualidade na formação dos profissionais da educação.

\section{REFERÊNCIAS}

AFONSO, A. J. Políticas educativas e autoavaliação da escola pública portuguesa: apontamentos de uma experiência. Estudos em Avaliação Educacional, São Paulo, v. 21, n. 46, p. 343-363, maio/ago. 2010.

AGUIAR, M. A. Políticas de currículo e formação dos profissionais da educação básica no Brasil: desafios para a gestão educacional. Espaço do Currículo, João Pessoa, v. 10, n. 1, p. 49-61, jan./abr. 2017. Disponível em: http://periodicos.ufpb.br/ojs2/index.php. Acesso em: 12 set. 2018.

AGUIAR, M. A. da S.; BRZEZINSKI, I.; FREITAS, H. L. C. L.; SILVA, M. S. P.; PINO, I. R. Diretrizes curriculares do curso de pedagogia no Brasil: disputas de projetos no campo da formação do profissional da educação. Educação \& Sociedade, Campinas, SP, v. 27, n. 96 (n. especial), p. 819-842, out. 2006. Disponível em: http://www.scielo.br/scielo.php?script=sci_ abstract\&pid=S0101-73302006000300010\&lng=en\&nrm=iso\&tlng=pt. Acesso em: 20 maio 2017.

ANDRÉ, M. Formação de professores: a constituição de um campo de estudos. Educação, Porto Alegre, v. 33, n. 3, p. 174-181, set./dez. 2010. Disponível em: http://revistaseletronicas.pucrs.br/ faced/ojs/index.php/faced/article/view/8075/5719. Acesso em: 25 maio 2017.

BARDIN, L. Análise de conteúdo. Lisboa: Edições 70, 2009.

BARRETO, E. S. de S. Políticas de formação docente para a educação básica no Brasil: embates contemporâneos. Revista Brasileira de Educação, Rio de Janeiro, v. 20, n. 62, p. 679-701, jul./set. 2015. Disponível em: https://www.scielo.br/pdf/rbedu/v20n62/1413-2478-rbedu-20-62-0679.pdf. Acesso em: 22 set. 2020.

BAZZO, V.; SCHEIBE, L. De volta para o futuro... Retrocessos na atual política de formação docente. Revista Retratos da Escola, Brasília, DF, v. 13, n. 27, p. 669-684, set./dez. 2019. Disponível em: http://retratosdaescola.emnuvens.com.br/rde/article/view/1038. Acesso em: 29 maio 2020.

BONAMINO, A.; SOUSA, S. Z. Três gerações de avaliação da educação básica no Brasil: interfaces com o currículo da/na escola. Educação e Pesquisa, São Paulo, v. 38, n. 2, p. 373-388, abr./jun. 2012. Disponível em: http://www.scielo.br/pdf/ep/v38n2/aopep633.pdf. Acesso em: 7 maio 2017. 
BRASIL. Ministério da Educação. Lei n. 9.394, de 20 de dezembro de 1996. Estabelece as Diretrizes e Bases da Educação Nacional. Lei n. 9.394/96. Brasília, DF, 1996. Disponível em: http://www. planalto.gov.br/ccivil_03/Leis/L9394.htm. Acesso em: 10 jul. 2020.

BRASIL. Ministério da Educação. Lei n. 10.861, de 14 de abril de 2004. Institui o Sistema Nacional de Avaliação da Educação Superior - SINAES e dá outras providências. Brasília, DF, 2004. Disponível em: http://www.planalto.gov.br/ccivil_03/_ato2004-2006/2004/lei/110.861.htm. Acesso em: 9 abr. 2020.

BRASIL. Ministério da Educação. Conselho Nacional de Educação. Conselho Pleno. Parecer CNE/ CP n. 5, de 13 de dezembro de 2005. Diretrizes Curriculares Nacionais para o Curso de Pedagogia. Brasília, DF, 2005.

BRASIL. Ministério da Educação. Conselho Nacional de Educação. Conselho Pleno. Parecer CNE/ CP n. 3, de 21 de fevereiro de 2006. Reexame do Parecer CNE/CP n. 5/2005, que trata das Diretrizes Curriculares Nacionais para o Curso de Pedagogia. Brasília, DF, 2006a. Disponível em: http:// portal.mec.gov.br/cne/arquivos/pdf/ pcp003_06.pdf. Acesso em: 22 set. 2020.

BRASIL. Ministério da Educação. Conselho Nacional de Educação. Conselho Pleno. Resolução CNE/CP n. 1, de 15 de maio de 2006. Institui as Diretrizes Curriculares Nacionais para o curso de graduação em pedagogia, licenciatura. Brasília, DF, 2006b. Disponível em: http://portal.mec.gov. br/cne/arquivos/pdf/rcp01_06.pdf. Acesso em: 3 nov. 2014.

BRASIL. Ministério da Educação. Parecer CNE/CP n. 2, de 9 de junho de 2015. Diretrizes Curriculares Nacionais para a Formação Inicial e Continuada dos Profissionais do Magistério da Educação Básica. Diário Oficial da União, Seção 1, p. 13, Brasília, DF, 2015a. Disponível em: http:// portal.mec.gov.br/index.php?option=com_docman\&view=download\&alias=17625-parecer-cne-cp-22015-aprovado-9-junho-2015\&category_slug=junho-2015-pdf\&Itemid=30192. Acesso em: 26 jul. 2021.

BRASIL. Ministério da Educação. Resolução n. 2, de $1^{\circ}$ de julho de 2015. Define as Diretrizes Curriculares Nacionais para a formação inicial em nível superior (cursos de licenciatura, cursos de formação pedagógica para graduados e cursos de segunda licenciatura) e para a formação continuada. Brasília, DF, 2015b. Disponível em: http://portal.mec.gov.br/index.php?option=com docman\&view=download\&alias=17719-res-cne-cp-002-03072015\&category_slug=julho-2015pdf\&Itemid=30192. Acesso em: 12 dez. 2016.

BRASIL. Ministério da Educação. Lei n. 13.415, de 16 de fevereiro de 2017. Altera a Lei n. 9.394, de 20 de dezembro de 1996, que estabelece as diretrizes e bases da educação nacional. Brasília, DF, 2017. Disponível em: http://www.planalto.gov.br/ccivil_03/_ato2015-2018/2017/lei/L13415.htm. Acesso em: 10 maio 2020 .

BRASIL. Ministério da Educação. Conselho Pleno. Parecer CNE/CES n. 22, de 7 de novembro de 2019. Diário Oficial da União, Seção 1, p. 142, Brasília, DF, 2019a. Disponível em: http://portal.mec. gov.br/index.php?option=com_docman\&view=download\&alias=133001-pcp022-19\&category_ slug=dezembro-2019-pdf\&Itemid=30192. Acesso em: 26 jul. 2021.

BRASIL. Ministério da Educação. Conselho Nacional de Educação. Conselho Pleno. Resolução CNE/ CP n. 2, de 20 de dezembro de 2019. Define as Diretrizes Curriculares Nacionais para a formação inicial de professores para a educação básica e institui a Base Nacional Comum para a formação inicial de professores da educação básica (BNC-Formação). Brasília, DF, 2019b. Disponível em: http:// portal.mec.gov.br/docman/dezembro-2019-pdf/135951- rcp002-19/file. Acesso em: 29 abr. 2020. 
BRZEZINSKI, I. Formação de professores para a educação básica e o curso de pedagogia: a tensão entre instituído e instituinte. Revista Brasileira de Política e Administração da Educação, Brasília, DF, v. 23, n. 2, p. 229-251, maio/ago. 2007.

BRZEZINSKI, I. Formação de professores: a dimensão política e o compromisso social do pedagogo como professor, investigador e gestor educacional. Revista Brasileira de Formação de professores, Cristalina, GO, v. 1, n. 3, p. 51-75, dez. 2009.

DOURADO, L. F. Diretrizes Curriculares Nacionais para a formação inicial e continuada dos profissionais do magistério da educação básica: concepções e desafios. Educação \& Sociedade, Campinas, SP, v. 36, n. 131, p. 299-324, abr./jun. 2015. Disponível em: http://www.scielo.br/pdf/es/ v36n131/1678-4626-es-36-131-00299.pdf. Acesso em: 22 set. 2018.

ESTEVES, M. Formação inicial de professores: saber mais para agir melhor. In: GREGÓRIO, M. C.; FERREIRA, S. Formação inicial de professores. Lisboa: Conselho Nacional de Educação, 2015. p. 156-165.

FERNANDES, D. Pesquisa de percepções e práticas de avaliação no ensino universitário português. Estudos em Avaliação Educacional, São Paulo, v. 26, n. 63, p. 596-629, set./dez. 2015. Disponível em: https://dialnet.unirioja.es/descarga/articulo/5619751.pdf. Acesso em: 7 mar. 2017.

FERNANDES, D. Ensino e avaliação no ensino superior: reflexões a partir da pesquisa realizada no âmbito do Projeto Avena. Cadernos Cedes, Campinas, SP, v. 36, n. 99, p. 223-238, maio/ago. 2016. Disponível em: http://www.scielo.br/pdf/ccedes/v36n99/1678-7110-ccedes-36-99-00223.pdf. Acesso em: 27 ago. 2017.

FLORES, M. A. Formação docente e identidade profissional: tensões e (des)continuidades. Educação, Porto Alegre, v. 38, n. 1, p. 138-146, jan./abr. 2015. Disponível em: https:// revistaseletronicas.pucrs.br/ojs/index.php/faced/article/view/15973. Acesso em: 28 set. 2020.

FORMOSINHO, J. A academização da formação de professores. In: FORMOSINHO, J. (coord.). Formação de professores: aprendizagem profissional e ação docente. Porto: Porto Editora, 2009. p. 73-92.

GATTI, B. A.; BARRETTO, E. S. S.; ANDRÉ, M. E. D. A. Políticas docentes no Brasil: um estado da arte. Brasília, DF: Unesco, 2011. 300 p.

GATTI, B. A. et al. Formação de professores para o ensino fundamental: instituições formadoras e seus currículos. São Paulo: Fundação Victor Civita, 2010. p. 95-138. (Estudos \& Pesquisas Educacionais, n. 1).

GEERTZ, C. The world in pieces. In: GEERTZ, C. Available light: anthropological reflections on philosophical topics. Princeton: Princeton University Press, 2000. p. 91-117.

GIRAUD, O. Comparação dos casos mais contrastantes: método pioneiro central na era da globalização. Sociologias, Porto Alegre, v. 11, n. 22, p. 54-74, jul./dez. 2009.

GOMES, S. dos S. Práticas de avaliação da aprendizagem e sua relação com a formação continuada de professores no cotidiano do trabalho escolar. Estudos em Avaliação Educacional, São Paulo, v. 16, n. 32, p. 111-144, jul./dez. 2005. Disponível em: http://publicacoes.fcc.org.br/index.php/eae/article/ view/2138. Acesso em: 29 jan. 2020. 
GOMES, S. dos S.; MELO, S. D. G. de. Políticas de avaliação e gestão educacional: articulações, interfaces e tensões. Educação \& Realidade, Porto Alegre, v. 43, n. 4, p. 1199-1216, out. 2018. Disponível em: http://www.scielo.br/scielo.php?script=sci_arttext\&pid=S217562362018000401199\&lng=en\&nrm=iso. Acesso em: 22 set. 2020.

HONÓRIO, M. G.; LOPES, M. S. L.; LEAL, F. L. S.; HONÓRIO, T. C. T.; SANTOS, V. A. As novas Diretrizes Curriculares Nacionais para formação inicial e continuada de professores da educação básica: entre recorrências e novas inquietações. Revista Ibero-Americana de Estudos em Educação, Araraquara, SP, v. 12, n. 3, p. 1736-1755, jul./set. 2017. Disponível em: https://doi.org/10.21723/riaee. v12.n.3.2017.8532. Acesso em: 22 set. 2019.

LEITE, E. A. P.; RIBEIRO, E. S.; LEITE, K. G.; ULIANA, M. R. Alguns desafios e demandas da formação inicial de professores na contemporaneidade. Educação \& Sociedade, Campinas, SP, v. 39, n. 144, p. 721-737, set. 2018. Disponível em: http://www.scielo.br/scielo.php?script=sci_ arttext\&pid=S0101-73302018000300721\&lng=en\&nrm=iso. Acesso em: 22 dez. 2019.

LIBÂNEO, J. C. Formação dos profissionais da educação: visão crítica e perspectivas de mudança. In: PIMENTA, S. G. Pedagogia e pedagogos: caminhos e perspectivas. São Paulo: Cortez, 2006. p. 11-57.

LIBÂNEO, J. C. A formação de professores no curso de pedagogia e o lugar destinado aos conteúdos do ensino fundamental: que falta faz o conhecimento do conteúdo a ser ensinado às crianças? In: SILVESTRE, M. A.; PINTO, U. de A. (org.). Curso de Pedagogia: avanços e limites após as Diretrizes Curriculares Nacionais. São Paulo: Cortez, 2017. p. 49-78.

LOPO, T. T. Entre dois regimes jurídicos, o que mudou no currículo da formação inicial de professores em Portugal? Arquivos Analíticos de Políticas Educativas, Arizona, v. 26, n. 24, p. 1-17, 18 jan. 2016. Disponível em: http://dx.doi.org/10.14507/epaa.24.2215. Acesso em: 12 set. 2020.

MANDARINO, M. C. F.; BELTRÃO, K. I. Licenciaturas no Brasil: cursos e formandos. Arquivos Analíticos de Politicas Educativas, Arizona, v. 26, n. 3, p. 1-30, jan. 2018. Disponível em: http://dx.doi.org/10.14507/epaa.26.3285. Acesso em: 29 set. 2020.

MANIFESTO DOS PIONEIROS. O Manifesto dos Pioneiros da Educação Nova. (1932). Revista HISTEDBR On-line, Campinas, SP, n. especial, p. 188-204, ago. 2006.

MASSON, G. As relações entre a agenda pós-moderna e os fundamentos das políticas de formação de professores no Brasil. Arquivos Analiticos de Politicas Educativas, Arizona, v. 19, n. 19, p. 1-21, 10 jul. 2011. Disponível em: http://epaa.asu.edu/ojs/article/view/764. Acesso em: 22 maio 2017.

NAKAMURA, P. H. A necessidade de estudos comparados na educação superior: o caso brasileiro. Revista Temas em Educação, João Pessoa, v. 22, n. 2, p. 14-24, jul./dez. 2013.

NÓVOA, A. Para una formación de profesores construida dentro de la profesión. Revista de Educación, Madri, n. 350, p. 203-218, set./dez. 2009a.

NÓVOA, A. Modelos de análise em educação comparada: o campo e o mapa. In: MARTINEZ, S. A.; SOUZA, D. B. (org.). Educação comparada: rotas de além-mar. São Paulo: Xamã, 2009b. p. 23-62.

PHILLIPS, D.; SCHWEISFURTH, M. Comparative and international education. An introduction to theory, method, and practics. 2. ed. London: Bloomsbury Publishing, 2014. 
PIMENTA, S. G. Pedagogia e pedagogos: caminhos e perspectivas. São Paulo: Cortez, 2006.

PIMENTA, S. G. et al. Os cursos de licenciatura em pedagogia: fragilidades na formação inicial do professor polivalente. In: SILVESTRE, M. A.; PINTO, U. de A. (org.). Curso de Pedagogia: avanços e limites após as Diretrizes Curriculares Nacionais. São Paulo: Cortez, 2017. p. 23-48.

PORTUGAL. Assembleia da República. Decreto-lei n. 74, de 24 de março de 2006. Aprova o regime jurídico dos graus e diplomas do ensino superior. Lisboa: AR, 2006. Disponível em: https://data. dre.pt/eli/dec-lei/74/2006/03/24/p/dre/pt/html. Acesso em: 26 jul. 2021.

PORTUGAL. Decreto-lei n. 43, de 22 de fevereiro de 2007. Institui regime jurídico da habilitação profissional para a docência na educação pré-escolar e nos ensinos básico e secundário. Diário da República, série 1, n. 38, p. 1320-1328, 22 de fevereiro de 2007a. Disponível em: https://dre.pt/ application/conteudo/517819. Acesso em: 18 set. 2018.

PORTUGAL. Ministério da Ciência, Tecnologia e Ensino Superior. Decreto-lei n. 369, de 5 de novembro de 2007. Institui a Agência de Avaliação e Acreditação do Ensino Superior. Diário da República, Lisboa, série 1, n. 212, p. 8032-8040, 2007b.

PORTUGAL. Assembleia da República. Lei n. 38/2007, de 16 de agosto. Aprova o regime jurídico da avaliação do ensino superior. Diário da República, Lisboa, série 1, n. 157, p. 5310-5313, 2007c.

PORTUGAL. Ministério da Ciência, Tecnologia e Ensino Superior. Decreto-lei n. 107, de 25 de junho de 2008. Republica o Decreto-lei n. 74, de 24 de março de 2006. Regime Jurídico dos graus acadêmicos e diplomas do ensino superior. Diário da República, Lisboa, série 1, n. 121, p. 3835-3853, 2008.

PORTUGAL. Ministério da Ciência, Tecnologia e Ensino Superior. Decreto-lei n. 79, de 14 de maio de 2014. Regime Jurídico da habilitação profissional para a docência na educação pré-escolar e nos ensinos básicos e secundário. Diário da República, Lisboa, n. 92, série 1, p. 2819-2828, 2014.

ROLDÃO, M. do C. Formação de professores na investigação portuguesa: um olhar sobre a função do professor e o conhecimento profissional. Revista Brasileira de Pesquisa sobre Formação Docente, Belo Horizonte, v. 1, n. 1, p. 57-70, ago./dez. 2009. Disponível em: https://revformacaodocente.com. br/index.php/rbpfp/article/view/v1n1_2c/4. Acesso em: 21 maio 2016.

SCHEIBE, L. Diretrizes curriculares para o curso de pedagogia: trajetória longa e inconclusa. Cadernos de Pesquisa, São Paulo, v. 37, n. 130, p. 43-62, jan./abr. 2007. Disponível em: http://www.scielo.br/scielo.php?script=sci_arttext\&pid=S0100-15742007000100004\&lng=pt\&nrm=i so. Acesso em: 29 maio 2020.

SOUSA, S. Z. Avaliação externa e em larga escala no âmbito do Estado brasileiro: interface de experiências estaduais e municipais de avaliação da educação básica com iniciativas do governo federal. In: BAUER, A.; GATTI, B. A. Ciclo de debates: vinte e cinco anos de avaliação de sistemas educacionais no Brasil. v. 2. Florianópolis: Insular, 2013. p. 61-85.

SOUSA, S. Z. Concepções de qualidade da educação básica forjadas por meio de avaliações em larga escala. Avaliação: Revista da Avaliação da Educação Superior, Campinas; Sorocaba, SP, v. 19, n. 2, p. 407-420, jul. 2014. Disponível em: http://www.scielo.br/pdf/aval/v19n2/a08v19n2.pdf. Acesso em: 22 set. 2017. 
SOUZA, D. B. de; BATISTA, N. C. Perspectiva comparada em políticas públicas de educação: Estudos Brasil-Espanha. Arquivos Analíticos de Políticas Educativas, Arizona, v. 25, n. 19, p. 1-43, 6 mar. 2017. Disponível em: https://epaa.asu.edu/ojs/article/view/2548. Acesso em: 10 set. 2020.

WELLER, W. Compreendendo a operação denominada comparação. Educação \& Realidade, Porto Alegre, v. 42, n. 3, p. 921-938, jul. 2017. Disponível em: http://www.scielo.br/scielo.php?script=sci_ arttext\&pid=S2175-62362017000300921\&lng=pt\&nrm=iso. Acesso em: 22 set. 2020.

\section{COMO CITAR ESTE ARTIGO}

GOMES, Suzana dos Santos; FERNANDES, Domingos; SOUSA, Sandra Zákia. Políticas de formação de professores e regulação de cursos em Portugal e no Brasil. Estudos em Avaliação Educacional, São Paulo, v. 32, e08437, 2021. DOI: https://doi.org/10.18222/eae.v32.8437 